\title{
ECONOMIA SOLIDÁRIA: ALTERNATIVA EMANCIPATÓRIA PARA AS MULHERES
}

\author{
SOLIDARY ECONOMY: EMANCIPATORY ALTERNATIVE FOR \\ WOMEN
}

\author{
Sharlene Dantas Moraes ${ }^{1}$ \\ Maria Josefa da Silva ${ }^{2}$ \\ Joanacele Gorgonho Ribeiro Nóbrega ${ }^{3}$ \\ Samara Alves Brito ${ }^{4}$ \\ Sheylla Nadjane Batista Lacerda ${ }^{5}$ \\ Lindalva Alves Cruz $^{6}$
}

\begin{abstract}
RESUMO: Objetivo: O estudo pretendeu-se analisar as experiências de ES autogestada por mulheres e identificar se tal prática se constitui, ao mesmo tempo, em base de organização econômica, política e social na construção da cidadania. Metodologia: Da perspectiva metodológica, recorreu-se à pesquisa qualitativa associada à quantitativa, porque ambas, não se contrapondo, poderiam ajudar a se apreenderem melhor os significados trazidos pelas mulheres. Resultados: Como o estudo é complexo, requer arcabouço teórico consistente no sentido de dar conta do que se propõe. Para tanto, buscou-se, por meio de debate feminista, que usa gênero como categoria analítica, e no debate sobre ES, averiguar duas questões: a) as organizações de economia solidária conduzidas por mulheres contribuem para o processo de organização social e política das trabalhadoras?; b) nesse movimento, elas vivenciam relações não hierárquicas que apontam para o fortalecimento da autonomia e da construção de direitos? Conclusão: Os dados expostos neste artigo
\end{abstract}

\footnotetext{
1 Graduada em serviço social pela Faculdade Santa Maria, Cajazeiras (PB), e pesquisadora voluntária do grupo de estudo e pesquisa GEPEGESC - FSM.

2 Bacharel em serviço social pela Faculdade Santa Maria, Cajazeiras (PB), Pós graduada em atendimento educacional especializado pela Unicoorp e pesquisadora voluntária do grupo de estudo e pesquisa GEPEGESC - FSM.

${ }^{3}$ Assistente social do IMJOB e membro do GEPEGESC - FSM.

${ }^{4}$ Doutora em ciências farmacêuticas pela UFPE e professora da Faculdade Santa Maria, Cajazeiras (PB), Brasil.

${ }^{5}$ Doutora em saúde pública pela Faculdade de Medicina do $A B C$, mestre em engenharia agrícola pela Universidade Federal da Paraíba, graduada em licenciatura em biologia pela Universidade Federal da Paraíba, diretora pedagógica da Faculdade Santa Maria, diretora da pós-graduação lato sensu da Faculdade Santa Maria. Atua na área de saúde pública e avaliação de serviços de saúde.

${ }^{6}$ Doutora em sociologia pela UFPE, professora da Faculdade Santa Maria, Cajazeiras (PB), Brasil, e coordenadora do GEPEGESC - FSM.
} 
não têm caráter conclusivo, pois, até o momento, não houve condições para conclusão da pesquisa; entretanto, sugerem que, na Paraíba, o movimento cresceu, e, na maioria dos casos, as mulheres os coordenam. Ao lado disso, os mesmos dados apontam para informalidade dos empreendimentos quando gestados por elas, o que dificulta o acesso aos recursos públicos. Ademais, evidencia-se certo conflito entre tarefas domésticas e espaço público da economia solidária. Hoje, em virtude do desmonte das políticas públicas, vivem-se "tempos sombrios" em relação à economia solidária.

Palavras chave: Cidadania. Economia solidária. Mulheres.

ABSTRACT: Objective: The study aimed to analyze the experiences of selfmanaged SS by women and to identify whether such practice is, at the same time, based on economic, political and social organization in the construction of citizenship. Methodology: From a methodological perspective, qualitative research associated with quantitative research was used, because both, if not opposed, could help to better understand the meanings brought by women. Results: As the study is complex, it requires a consistent theoretical framework in order to account for what is proposed. To this end, we sought, through feminist debate, which uses gender as an analytical category, and in the debate on higher education, to investigate two questions: a) solidarity economy organizations led by women contribute to the process of social and political organization of women workers?; b) in this movement, do they experience non-hierarchical relationships that point to the strengthening of autonomy and the construction of rights? Conclusion: The data exposed in this article are not conclusive in character, as, to date, there have been no conditions for completing the research; however, they suggest that, in Paraíba, the movement has grown, and in most cases, women coordinate them. Alongside this, the same data points to the informality of the ventures when managed by them, which makes access to public resources difficult. In addition, there is a certain conflict between domestic tasks and the public space of the solidarity economy. Today, due to the dismantling of public policies, there are "dark times" in relation to the solidary economy.

Keywords: Citizenship. Solidarity economy. Women. 


\section{INTRODUÇÃO}

O desenvolvimento da economia solidária traz em seu bojo aspectos que chamam a atenção dos pesquisadores: a crescente participação das mulheres do meio popular na organização política, na gestão, na produção e na comercialização. Tais trabalhadoras eram ignoradas como sujeitos políticos (Cruz, 2013) e sentem a disparidade salarial nos espaços do emprego formal (Hirata, 2003). A verdade é que os empreendimentos de economia solidária parecem conduziras empreendedoras para fora do anonimato e apontar para outro tipo de relação na produção, no consumo e na venda dos produtos; além disso, possibilitam o contato com diferentes grupos que comungam os mesmos ideais quer no processo da formação coletiva, quer nas feiras promovidas pelos regionais, nos fóruns e nas assembleias.

A pesquisa foca a ação coletiva das mulheres que se organizam nos empreendimentos de economia solidária, para produção de louças de cerâmica, fabricação de doces caseiros, cultivo de hortaliças sem agrotóxico, trabalho de reciclagem, confecção de artesanatos, dentre outros, no sentido de averiguar duas questões fundamentais: a) as organizações de economia solidária conduzidas por mulheres contribuem para o processo de organização social e para a política das trabalhadoras?; b) nesse movimento, elas vivenciam relações não hierárquicas que apontam para o fortalecimento da autonomia e da construção de direitos? No texto a seguir, é possível perceber que os atores (as mulheres) que configuram tal modelo são muito distintos dos atores dos primórdios.

\section{Economia solidária: alternativa econômica e societária}

Do ponto de vista conceitual, não há definição única do termo economia solidária; contudo, segundo Singer (2003), todas as tentativas nesse sentido giram 
em torno da ideia de solidariedade em contraste com o individualismo. Conforme Ortiz (2001), a economia solidária recobre diferentes formas de organização nas quais os (as) cidadãos(as) se propõem criar as próprias fontes, a fim de ter acesso a bens e serviços que articulem os interesses individuais e coletivos (tradução livre). Singer (2002), por sua vez, esboça uma forma de entendimento, afirmando que ela é um

modelo de produção e distribuição alternativa ao capitalismo, criado e recriado periodicamente pelos que se encontram marginalizados do mercado de trabalho [...] essa atividade casa o princípio da unidade entre posse e uso dos meios de produção e distribuição com o princípio da socialização destes meios (p. 12).

Segundo o Fórum Brasileiro de Economia Solidária (FBES), tal prática pode ser definida em três dimensões: econômica, cultural e política. Do ponto de vista econômico, ela é "um jeito de fazer a atividade econômica de produção, oferta de serviços, comercialização, finanças ou consumo baseado na democracia e na cooperação, o que chamamos de autogestão". Em relação à dimensão cultural, o FBES (2011) destaca que

é também um jeito de estar no mundo e de consumir produtos locais, saudáveis, da Economia Solidária, que não afetem o meio ambiente, que não tenham transgênicos e nem beneficiem grandes empresas. Neste aspecto, também simbólico e de valores, estamos falando de mudar o paradigma da competição para o da cooperação da inteligência coletiva, livre e partilhada".

Quanto à dimensão política, define-se como

um movimento social, que luta pela mudança da sociedade, por uma forma diferente de desenvolvimento, que não seja baseado nas grandes empresas, mas sim um desenvolvimento para as pessoas, construído pela população a partir dos valores da solidariedade, da democracia, da cooperação, da preservação ambiental e dos direitos humanos. [...] é praticada por milhões de trabalhadoras e trabalhadores de todos os extratos, incluindo a população mais excluída e vulnerável, organizados de forma coletiva gerindo seu próprio trabalho, lutando pela sua emancipação em milhares de empreendimentos econômicos solidários e garantindo, assim, a reprodução ampliada da vida nos setores populares [...] 
composta de redes e organizações de uma diversidade de práticas associativas do segmento popular solidário: rural, urbano, estudantes, igrejas, bases sindicais, universidades, práticas governamentais de políticas sociais, práticas de apoio ao crédito, redes de informação e vinculo às redes internacionais. (FBES, 2011).

O protótipo da economia solidária encontra-se no início do século XIX, quando também se desenvolvia a experiência capitalista de acumulação. A produção coletiva foi uma forma de se contrapor aos princípios do capitalismo, que, em vez de produzir para suprir as necessidades humanas, produzia para acumular riquezas. Segundo Robert Owen apud Polanyi (1980), o novo capitalismo havia causado não só o empobrecimento material dos trabalhadores, mas também o rompimento da cultura ética à qual os trabalhadores pertenciam e por meio da qual definiam a sua identidade. De acordo com Polanyi (1980), Owen foi um dos primeiros autores a reconhecer que as instituições econômicas têm impacto no autorreconhecimento cultural das pessoas.

A experiência nas cooperativas buscava a valorização do ser humano e, ao mesmo tempo, a inserção no mercado de trabalho dos operários excluídos, explorados e marginalizados pelo modo de produção capitalista. $O$ único pensador que percebeu a raiz do problema - ressalta Polanyi - foi Robert Owen (1771-1858), para quem a superação dos desafios estava na sociedade, e não no mercado. Ele e os pensadores de seu tempo, a exemplo de Willian King (1786-1865) e Charles Fourier (1772-1837), criaram uma forma de pensar que fundamentou o cooperativismo em todo o mundo: o homem deve construir, na sociedade em que vive, outra maneira de processar a economia, baseando-se no trabalho e na distribuição equitativa do excedente adquirido, sem acumulação individual do dinheiro originada na exploração do trabalho.

Para Polanyi (1980), no século XIX, já havia movimentos a expressar reação contra o transtorno que atacava o tecido da sociedade e teria destruído a própria organização criada pelo mercado. $O$ autor se refere, principalmente, às duas correntes de pensamento opostas ao sistema capitalista: o socialismo - contrário à propriedade privada - e o intervencionismo, que propunha a harmonia entre os interesses privados e os sociais. Essa corrente, da qual nasceu o cooperativismo, foi denominada por Marx de socialismo utópico (Garcia, 2002). 
$\mathrm{Na}$ Inglaterra e nos Estados Unidos, berço das várias comunidades ou aldeias cooperativas, são referências as experiências dessas organizações lideradas pelo movimento sindical, muitas vezes, fracassadas em virtude da feroz reação da classe patronal e da declarada hostilidade do governo (Garcia, 2002, pp. 73-77). A mais famosa cooperativa de consumo (dos pioneiros equitativos de Rochedale) estabeleceu uma carta de princípios que ainda inspira o cooperativismo e sua legislação em âmbito mundial. Em linhas gerais, podemos assim apresentá-los: 1) livre adesão e livre desistência; 2) controle democrático; 3) neutralidade política e religiosa; 4) vendas à vista, em dinheiro; 5) devolução de excedentes; 6) interesse limitado sobre o capital; 7) educacão contínua (Singer, 2000). Tais princípios, institucionalizados, asseguram a dinâmica democrática e coletiva do movimento econômico solidário que ressurge nas diversas ondas de crise econômica, com atores e promotores diferentes, variando de geração a geração, de um lugar para outro (Singer, 2000 e Sousa, 1990).

No Brasil, as primeiras cooperativas se construíram por volta de 1887 - as mais relevantes foram a Cooperativa de Consumo dos Empregados da Companhia Paulista, em Campinas (SP), e a Sociedade Econômica Cooperativa dos Funcionários Públicos de Minas Gerais (Schneider, 1982). A crise econômica mundial de 1929 estimulou a emergência de outras, especialmente as agrícolas no sul do país, que fizeram o governo se interessar pelo cooperativismo bem como considerá-lo instrumento de política agrícola. No entanto, só a partir de 1932, com a implantação do Decreto ํㅜ 22.239, no governo de Getúlio Vargas, regulamentou-se a organização e o funcionamento de tal modelo. A partir da década seguinte, os governos passaram a oferecer vários incentivos materiais e fiscais às cooperativas, o que, de certo modo, provocou a criação, em 1951, do Banco Nacional de Crédito Cooperativo (BNCC). Contudo, nas décadas posteriores, os governos foram perdendo o estímulo por essas organizações, até que, no governo de Fernando Collor, o BNCC fechou (Schneider; Vicente, 1996). Só em meados da década de 1990 é que elas voltaram a se fortalecerem decorrência da instabilidade do emprego (Schneider, 1982).

Nessa conjuntura, tornaram-se mais evidentes as ações coletivas com questões e demandas diferenciadas. Os novos sujeitos sociais, que emergiram na 
cena política na década de 1980 (Sader, 1996), reinventaram formas diferentes de produção e, na incansável luta pelos direitos básicos, congregaram também especificidades no mesmo patamar dos "novos movimentos sociais", os quais, com sua ação coletiva, têm buscado consolidar nova cultura econômica, política e de gênero. Essa outra forma de relação social visava à valorização do ser humano explorado e marginalizado pelo modo de produção capitalista.

O processo eleitoral no final de 2002 culminou com a vitória do candidato Lula à Presidência da República. De pronto, o Grupo de Trabalho Brasileiro de Economia Solidária (GT) - composto de redes e organizações de uma diversidade de práticas associativas do segmento popular solidário, a exemplo das organizações rurais e urbanas, dos estudantes, das igrejas, das bases sindicais, das universidades, das práticas governamentais de políticas sociais, das práticas de apoio ao crédito, das redes de informação vinculadas às redes internacionais - elaborou uma carta ao governo federal intitulada Economia solidária como estratégia política de desenvolvimento (FBES, 2003). A referida carta serviu como documento de interlocução entre as organizações citadas e o presidente recém-eleito. Ela continha as diretrizes gerais da economia solidária e a reivindicação da criação da Secretaria Nacional de Economia Solidária (SENAES). Os passos posteriores se direcionaram à criação do Fórum Brasileiro de Economia Solidária (FBES) no ano de 2003. Em seguida, ainda no primeiro mandato do presidente Lula, criou-se, no âmbito do Ministério do Trabalho e Emprego, a SENAES, principal articuladora política desses interesses na esfera governamental. Posteriormente, criaram-se também o Conselho Nacional de Economia Solidária e diversos fóruns estaduais.

Tais órgãos é que dinamizam, nas diferentes instâncias, as condições de funcionamento dos empreendimentos econômicos solidários, identificados pelas seguintes características: 1) coletivos (organizações suprafamiliares, singulares e complexas, tais como associações, cooperativas, empresas autogestionárias, clubes de trocas, redes, grupos produtivos, dentre outros); 2) participantes ou sócias(os)trabalhadoras(es) dos meios urbano e ou rural que exercem coletivamente a gestão das atividades assim como da alocação dos resultados (FBES, 2008).

Segundo Singer (2000), a empresa solidária difere da empresa capitalista em vários aspectos. O principal consiste na forma de administrá-las: a primeira tem 
como princípio a autogestão, ou seja, há democratização entre os sócios integrantes e todos devem estar informados sobre tudo que ocorre no interior da organização; a segunda adota a socialização no processo de produção e a apropriação privada do que é produzido.

O modelo da economia solidária, enfim, se constitui em proposta de desenvolvimento includente, realizável em sistema de autogestão, por meio de cooperativas, associações e grupos informais, assumida por seus constituintes como estratégia contra o desemprego, pautada em racionalidade não capitalista das relações de produção e de troca de bens e serviços (Singer, 2002). Contudo, lamentavelmente, em 2016, após o golpe que destituiu a presidenta Dilma, a Secretaria Nacional de Economia Solidária foi extinta e substituída pela subsecretaria de economia solidária inserida na Secretaria de Relações do Trabalho, no Ministério do Trabalho, o que ocasionou a demissão de Paul Singer (Arcanjo; Oliveira, 2017) - o mais admirável no movimento de economia solidária, então substituído por um administrador sem compromisso com tal movimento. Este passou a operar sem consultar os fóruns já constituídos, golpeando, assim, o princípio da autogestão (Arcanjo; Oliveira, 2017).

\section{Gênero e economia solidária e a desconstrução das relações de dominação}

As relações de dominação advindas do modelo patriarcal fizeram a família ser compreendida como um todo homogêneo em que o homem representa os interesses do conjunto, detentor do poder de decisão. Em outras palavras, na família, organizou-se uma hierarquia de gênero e geração centrada no poder do macho sobre as mulheres e filhos(as). Essas relações patriarcais, associadas à lógica da produção capitalista, entrelaçam-se e constituem uma visão da economia e do trabalho no âmbito de mercado. Reduz-se o econômico ao realizado na esfera produtiva, que possui valor de troca, pode ser mercantilizado e é identificado como espaço masculino (Saffioti, 2005). 
Tal visão se sustenta no discurso em que as mulheres são destinadas à esfera privada como parte de seu destino biológico, vinculado à maternidade. Isso reforça o não reconhecimento da produção doméstica e do papel econômico do trabalho das mulheres na família (Nobre, 2002; Silva, 2009; Strassmann, 2002). Essa realidade, cultivada ideologicamente como fruto da natureza, na verdade, é estruturada pela relação social específica entre homens e mulheres, a qual reflete uma forma de divisão do trabalho: a divisão sexual do trabalho. Segundo Kergoat (1996), tal divisão se organiza submetida a dois princípios: separação de trabalho de homem e de mulher e hierarquização do trabalho (o de homem é o mais valorizado). Disso decorrem práticas sociais distintas que atravessam todo o campo social. Uma sociedade sexuada, estruturada transversalmente pelas relações de gênero, admite a "discriminação das mulheres pelo trabalho mais valorado dos homens" (Hirata; Kergoat, 2003, p. 30).

No Brasil, a realidade descrita começou a ter outros contornos a partir da centralidade do debate sobre a categoria analítica gênero nas diferentes organizações das mulheres, que tiveram alguns direitos, como sociais, culturais, econômico, reconhecidos por meio da Constituição Federal de 1988.Embora o movimento de economia solidária não seja ação coletiva exclusiva de mulheres, pesquisas apontam grande participação delas na gestão e na comercialização de produtos (Costa, 2011).

A organização das mulheres no âmbito da economia solidária é uma reação contemporânea que vem ganhando maior visibilidade. No Brasil, por exemplo, só a partir da década de 1970, é que se encontram registros mais significativos a respeito do engajamento delas nas organizações populares e de sua luta incansável por democracia, por liberdade política e por direitos sociais (Alvarez, 1988 e 2001). Nesse contexto, a economia solidária emergiu como alternativa e compatível com a proposta de superação do modo de produção capitalista, apesar de que, para alguns autores, o novo modelo seja paradoxal (Menezes, 2005).

Nesta pesquisa, adotamos as ideias defendidas por Singer (2002), para quem a economia solidária ultrapassa a dimensão socioeconômica, pois busca congregar trabalhadores marginalizados do mercado formal por questões de gênero, raça, 
etnia, geração e qualificação profissional, o que configura nova visão política e econômica de construção da riqueza (Singer, 2002).

\section{A economia solidária na Paraíba e o perfil dos empreendimentos pesquisados}

Na Paraíba, não foram encontrados trabalhos publicados que esclarecessem a recente situação da economia solidária nem identificados os grupos; porém, de acordo com os dados da SIES (2009), ela vem proporcionando importante alternativa para o desenvolvimento da potencialidade produtiva de diferentes grupos e oferecendo oportunidade de gerar emprego e renda. Os mesmos dados revelam que tal prática já abrange todas as mesorregiões do estado - sinaliza, segundo informações colhidas nas publicações da Secretaria Nacional de Economia Solidária, que as mulheres são responsáveis por $90 \%$ das iniciativas, entre grupos de produção, associações e cooperativas.

Tais empreendimentos estão distribuídos nas regiões agreste, do Cariri, da mata paraibana e do sertão, onde há atividades de produção diversificadas. Alguns estão organizados em forma de associação; outros, em cooperativas; outros ainda em forma de grupos, na maioria, informais.

A pesquisa em tela levantou o perfil de 20 empreendimentos denominados economia solidária. No material colhido, identificaram-se algumas categorias que contribuíram para apontar respostas a importantes questionamentos, como: qual o número de homens e de mulheres em cada empreendimento? Quem faz a coordenação? Que tipo de formação os grupos recebem? Estão legalizados? Qual o tipo de produção? De onde vem o financiamento? Qual a renda mensal dos integrantes? Quais suas maiores dificuldades e suas conquistas? (Figura 1). 


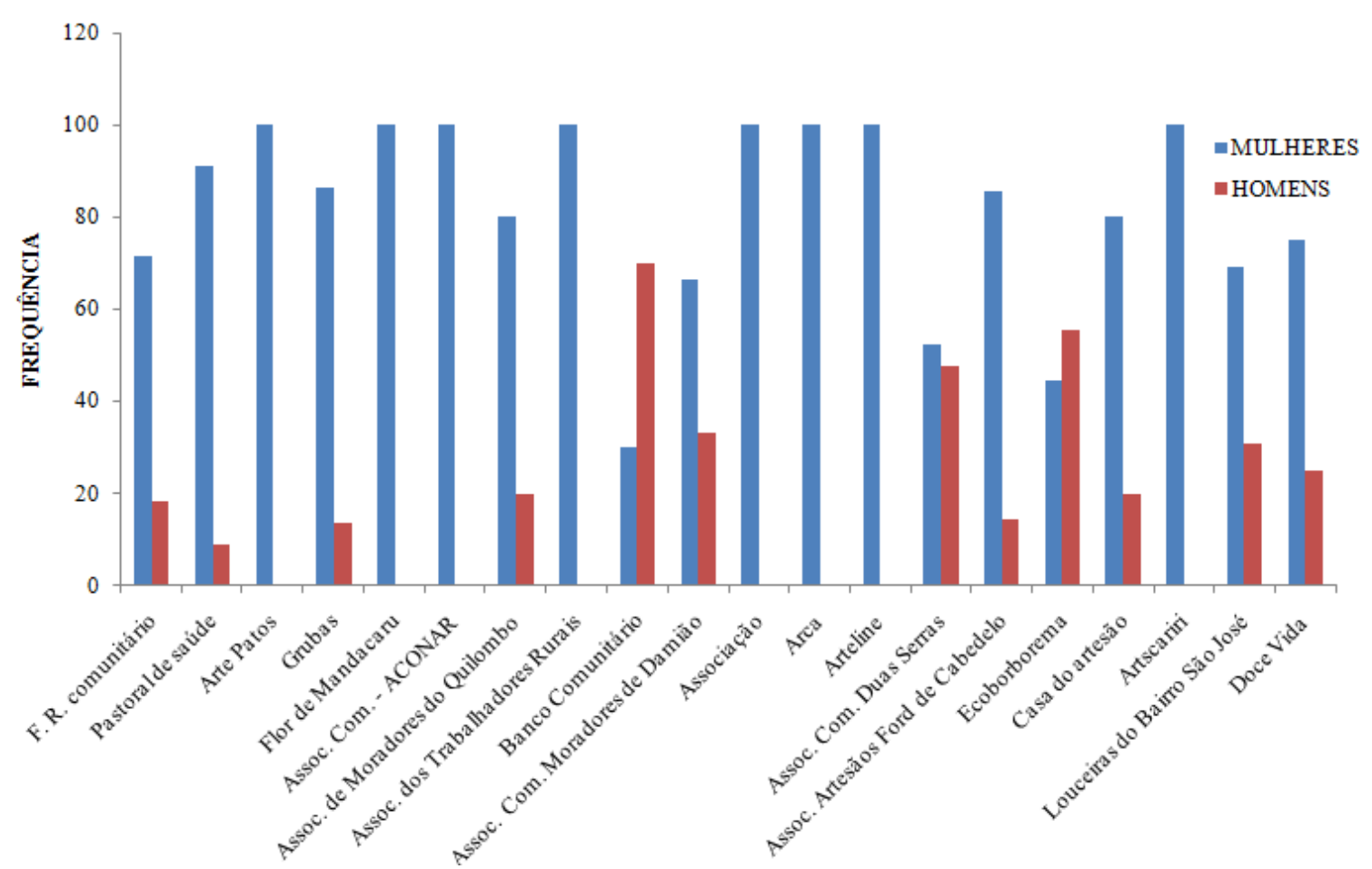

Figura 1. Empreendimentos mapeados. Fonte: GEPEGESC, 2017.

Os dados apresentados na figura 1 revelam a participação de homens e mulheres em cada empreendimento. Apesar de ser pequena a amostra, as informações apontam expressiva participação das mulheres $(70 \%$ contra $30 \%$ dos homens). E entre os grupos pesquisados, vale ressaltar, havia organizações constituídas apenas por mulheres.

Quanto à coordenação dos cooperados, 18 deles eram liderados por mulheres e apenas dois, por homens. Nesse quesito, a realidade das mulheres na economia solidária se contrapõe à apresentada por Hirata (2013) em seu vasto trabalho, em diferentes países. Quando inseridas, em massa, no mercado de trabalho capitalista, na maioria das vezes, era "para realizar tarefas secundárias que dispensassem o uso da força física, uma forma para justificativa da desvalorização do trabalho feminino na esfera da produção" (p. 113).

No quesito formação (figura 2), percebe-se clara preocupação dos regionais no sentido de que ela alcançasse todos os membros dos grupos. De acordo com as entrevistadas, tal formação se tem processado por meio dos encontros, dos fóruns, das feiras, dentre outros. Os temas destacados foram: economia solidária, 
assistência técnica, cooperativismo, autogestão, questões de gênero, questões ambientais e assessoria em marketing. Nesse processo, percebe-se o fortalecimento das redes mediante reciprocidade que realimenta os empreendimentos, a cultura solidária e a ética.

A relação entre as pessoas e o aprendizado coletivo resultante das próprias experiências são elementos essenciais para reestabelecer a solidariedade como elemento referencial. Segundo Costa (2011), "as redes de colaboração solidária referem-se à relação entre pessoas e empreendimentos como condição de possibilidade de viabilidade econômica e social" (p. 21).

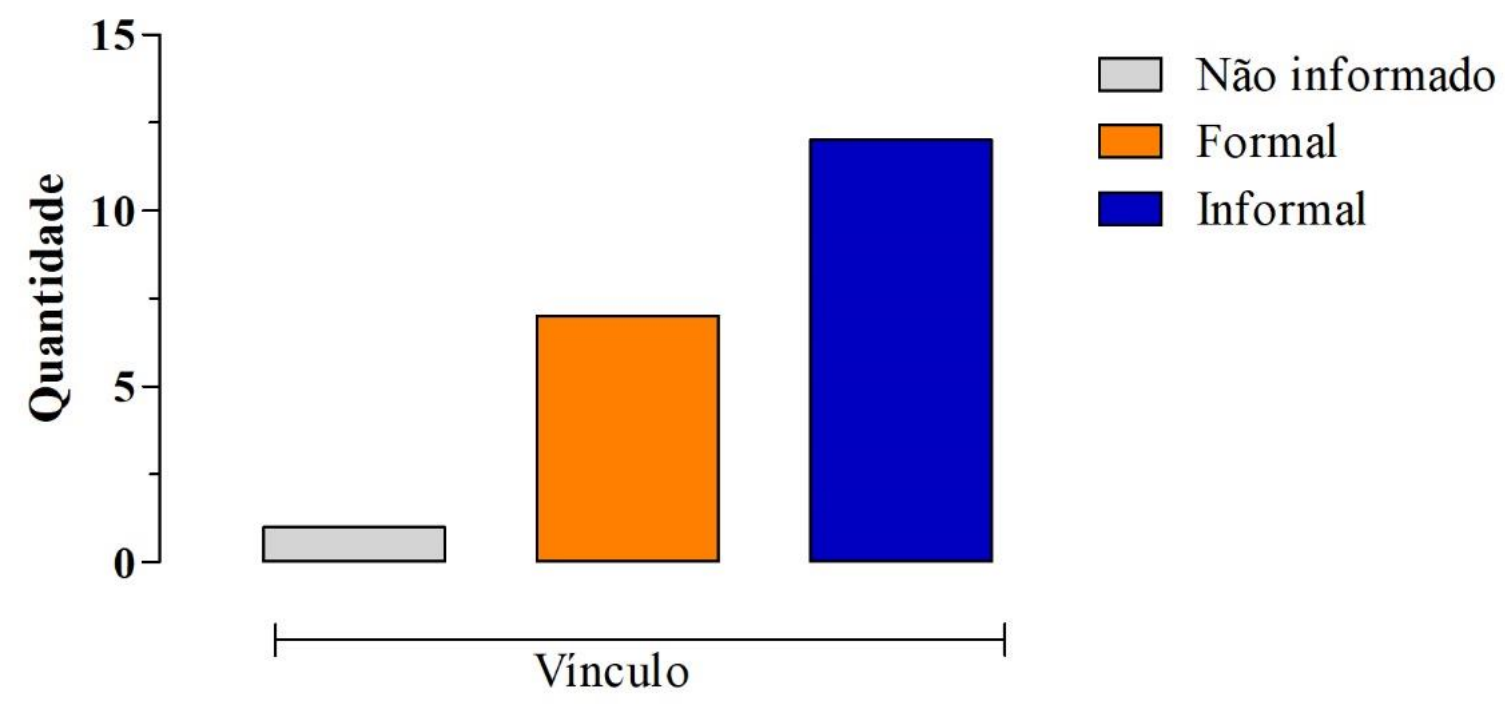

Figura 2. Formalidade dos empreendimentos. Fonte: GEPEGESC, 2017.

Se, por um lado, os dados com relação à participação das mulheres são animadores, por outro, deixam apreensão, pois, em vez de apontarem a autonomia das mulheres na produção na economia solidária, demonstram que os grupos nos quais elas têm maior participação que os homens estão na informalidade conforme figura 2. Essa realidade sugere ausência das políticas públicas ou de financiamento de outra natureza, pelo fato de os empreendimentos não possuírem registro ou documentos de identificação exigidos pelas instituições financeiras.

Segundo o IPEA (2009, p. 47), "a formalização de qualquer tipo de empresa é dispendiosa em dinheiro e exaustiva em esforço e paciência por causa das inúmeras exigências burocráticas das Juntas Comerciais, em que o registro tem de ser feito". 
A implicação maior nesse caso é que empreendimentos informais estão condenados a comercializar com outros nas mesmas condições. Assim, relega-se a produção a um consumo mais periférico.

Em relação ao financiamento da produção, trata-se de um dos maiores desafios, pois, segundo Singer (2008), o sistema financeiro é "antipobre". Os pequenos empreendimentos não respondem às exigências jurídicas nem têm garantias sólidas para atrair os investimentos do sistema financeiro formal. Por exemplo, quando analisamos as respostas para a pergunta referente ao financiamento da produção, 17 deles responderam que o financiamento provinha do próprio grupo (fundo rotativo). Dos outros três, dois afirmaram que recebiam financiamentos públicos e um recebia recursos de ONG internacional. Como se pode depreender, não há financiamento público para os empreendimentos, apesar de a Secretaria Nacional de Economia Solidaria (SENEAS) estar profundamente empenhada na política do microcrédito por meio do Banco Nacional do Desenvolvimento o (BNDES).

Quanto ao tipo de produção (figura 3), 13 dos empreendimentos pesquisados estavam com a produção voltada para o artesanato de bordado, crochê, renda e costuras; um deles, para louças de argila; e sete mesclavam sua produção entre artesanato e produtos alimentícios, como doces, polpas de fruta, criação de pequenos animais e hortaliça.

No tocante à renda, sua distribuição nos empreendimentos pesquisados apresentava uma realidade muito indefinida conforme se vê na figura 3 : 


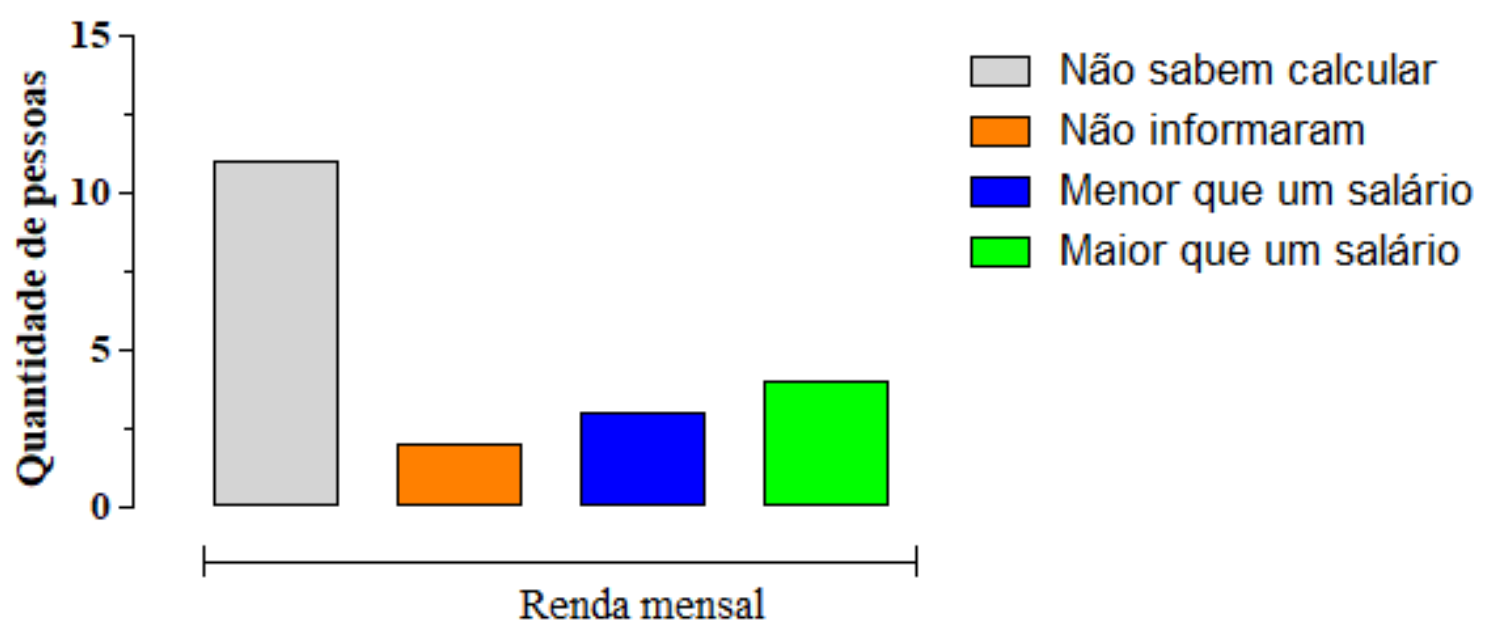

Figura 3. Renda mensal nos empreendimentos pesquisados. Fonte: GEPEGESC, 2017.

A maioria dos empreendimentos não utilizava o serviço de contabilidade, não fazia o controle das entradas e das saídas, para saber se estavam conseguindo sobras (palavra usada para o que restara dos investimentos). Desse modo, tornavase difícil saber o arrecadado durante o mês e quanto cabia a cada membro. Isso parece refletir-se na figura 3: 55\% afirmaram que não sabiam calcular; 10\% não informaram nada; $20 \%$ disseram que recebiam mais de um salário mínimo mensal e $15 \%$, menos de um salário mínimo. Mesmo assim, havia variação conforme as vendas em cada mês.

Quando perguntados pelas maiores dificuldades, as respostas foram unânimes: falta de apoio dos órgãos públicos; falta de capital de giro; burocracia para o registro sanitário; falta de local adequado para a comercialização; ausência de infraestrutura nos empreendimentos para aprimorar a produção; trabalhadores (as) sem a proteção social do trabalho. Os dados revelam que, mesmo havendo, no âmbito dos governos federal e estadual, sinais de apoio à economia solidária, na Paraíba isso é pouco sentido.

Apesar das dificuldades, as entrevistadas nos apresentaram elementos positivos. Quando perguntadas sobre as conquistas relevantes, as mais mencionadas (por 18 grupos) foram a autogestão pelas próprias mulheres e o 
exercício da democracia realizado por todos os integrantes dos grupos; em seguida, a geração de renda, apontada pelas trabalhadoras como uma conquista econômica e social delas. Sentiam-se, por isso, mais incluídas. Outro dado relevante é o comprometimento social e político das mulheres bem como a possibilidade de estarem juntas promovendo melhorias à comunidade. Merece registro ainda a formação que elas têm recebido e o crescimento da consciência política e de gênero.

\section{CONSIDERAÇÕES FINAIS}

O estudo não permitiu, ainda, emitir resultados conclusivos, pois a pesquisa está em andamento à espera de recursos para ser concluída, porém é possível apontar alguns elementos positivos, como, por exemplo, as mulheres já desenvolviam atividades fora das tarefas comumente atribuídas a elas. Tais ações constituem alternativa nas relações de trabalho, na formação e no exercício da democracia; desabrocham a consciência crítica e de gênero; põe em prática a autogestão, a construção coletiva; retiram a trabalhadora do isolamento e do anonimato. Esse avanço rumo à cidadania traz benefícios também para a comunidade. Contudo, vale ressaltar, tal avanço está longe de assegurar-Ihes os direitos almejados. Elas enfrentam grandes desafios, sobretudo, pelo baixo nível de escolaridade, pelo desconhecimento das políticas públicas, pela sobrecarga das tarefas domésticas e pelo não acesso às instituições de fomento financeiro. Além do mais, falta-Ihes o conhecimento operacional para comercialização, estabelecimento de preços e elaboração de projetos. Neste momento da pandemia, ficou mais difícil ainda. Ainda assim, a liderança e o dinamismo das mulheres têm sido fundamentais para manter os empreendimentos, em cuja maioria elas vêm assumindo a liderança. As dificuldades são muito maiores, pois a política econômica revela-se alheia aos trabalhadores e muito mais voltada à proteção do grande capital, o que contribui para reformas trabalhistas e descaso às iniciativas populares. 


\section{REFERÊNCIAS BIBLIOGRÁFICAS}

Alvarez, S. A. (1988). Politizando as relações de gênero e engendrando a democracia. In A. Stefan (Org.), Democratizando o Brasil (pp. 315-380). Rio de Janeiro: Paz e Terra.

Alvarez, S. E.; Dagnino, E.; Escobar, A. (2001). Cultura e política nos movimentos sociais latinoamericanos (novas leituras). Belo Horizonte: UFMG.

Arcanjo, M. A. S. de; Oliveira, A. L. M.de. (2017). A criação da Secretaria Nacional de Economia Solidária: avanços e retrocessos. Perseu, São Paulo, ano 13, n. 11, p. 231-249.

Brasil. IBGE. Instituto Brasileiro de Geografia e Estatística. (2010). Retirado de <www.ibge.gov.br/catálogos/indicadores>. Acessado em junho 2010.

Brasil. Secretaria Nacional de Economia Solidária. (2008). Retirado de http://www.mte.gov.br/ecosolidaria/secretaria_nacional.asp. Acessado em 06 de fevereiro de 2008.

Brasil. Secretaria Nacional de Economia Solidária. (2006). Iª Conferência Nacional de Economia Solidária. Anais. Brasília: SENAES/TEM.

Brasil. SENAES. Secretaria Nacional de Economia Solidária. (2005). Oficina Nacional de Formação/Educação em Economia Solidária. Relatório Final. Brasília: SENAES/TEM.

Cappellin, G. P. (1989). Silenciosas e combativas: as contribuições das mulheres na estrutura sindical do Nordeste, 1976/1986. In A. O. Costa; C. Bruschini (Orgs.), Rebeldia e submissão: estudos sobre a condição feminina (pp. 255-300). São Paulo: Vértice.

Carrasco, C. (1999). Mujeres y economía. Nuevas perspectivas para viejos problemas. Barcelona: Icaria.

Cordeiro, R. L. M. (2006). Além das secas e das chuvas: O uso da nomeação trabalhadora rural no sertão de Pernambuco. In E. F. Woortmann; B. Heredia; R. Menashe (Orgs.), Estudos rurais e gênero (pp.216-214). Brasília: NEAD.

Cordeiro, R. L. M. (2004). Além das secas e das chuvas: o uso da nomeação trabalhadora rural no sertão de Pernambuco. Tese de doutorado, Universidade Católica de São Paulo, São Paulo.

Cruz, L. A. (2013). Construção da cidadania das mulheres trabalhadoras rurais no Piauí. Fortaleza: Banco do Nordeste do Brasil.

Deere, C. D.; León, M. (2002). O empoderamento da mulher; direitos à terra e direitos de propriedade na América Latina. Porto Alegre: Editora da UFRGS.

Fischer, I. R. (2006). O protagonismo da mulher rural no contexto da dominação. Recife, Fundação Joaquim Nabuco: Massangana.

Fórum Brasileiro de Economia Solidária. (2011). Economia solidária, gestão coletiva, resultados compartilhados.

Hirata, H.; Kergoat, D. (2003). A divisão sexual do trabalho revisitada. In M. Maruani; H. Hirata (Orgs.), As novas fronteiras da desigualdade homens e mulheres no mercado de trabalho (pp. 111-123). São Paulo: SENAC. 
Júnior, S. L. V. (2008). O movimento da economia solidária: a emergência de um movimento social pela humanidade. In/II Mostra de Pesquisa da Pós-Graduação - PUCRS.

Kergoat, D. (1996). Relações sociais de sexo e divisão sexual do trabalho. In M. Lopes; D. Meyer; V. Waldow (Orgs.), Gênero e saúde (p. 156). Porto Alegre: Artes Médicas.

Menezes, M. T. C. G. (2007). Economia solidária: elementos para uma crítica marxista. III Jornada Internacional de Políticas Públicas Questão Social e Desenvolvimento no Século XXI.

Menezes, M. T. C. G. (2005). Economia solidária: elementos para uma crítica marxista. Tese de doutorado. Universidade Federal do Rio de Janeiro, Rio de Janeiro.

Minayo, M. C. S. (1994). O desafio do conhecimento: pesquisa qualitativa em saúde. São Paulo Rio de Janeiro: HUCITEC-ABRASCO.

Nobre, M. (2002). Introdução a economia feminista. In M. Nobre; N. Faria (Orgs.). Economia feminista. Cadernos Sempre Viva. SOF, São Paulo.

Ortiz Roca, H. (2001). Economia solidária, hacia una nuevacivilización. Lima.

Pinto, C. R. J. (2003). Uma história do feminismo no Brasil. São Paulo: Fundação Perseu Abramo.

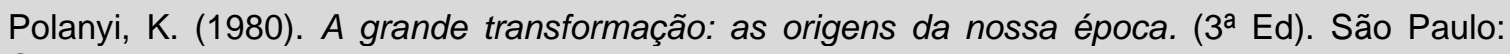
Campus.

Sader, E. (1988). Quando novos personagens entram em cena. Rio de Janeiro: Paz e Terra.

Saffioti, H. I. B. (2005). Gênero e patriarcado: a necessidade da violência. In M. C. Martin; S. Oliveira. (Orgs.). Marcadas a ferro: violência contra a mulher uma visão multidisciplinar. Brasília: Secretaria Especial de Políticas para as Mulheres.

Schneider, J. O. (1982). O panorama mundial, nacional e estadual do cooperativismo. In: Perspectiva Econômica. São Leopoldo, no12, 9-46.

Schneider, J. O; Vicente, J. H. V. (1996). A reestruturação produtiva e as cooperativas de trabalho. In: Perspectiva Econômica. São Leopoldo, v.31 no 94.

Scherer, W., I. (2006). Das mobilizações às redes de movimentos sociais. Sociedade e Estado, $21,109-130$.

Scott, J. (2005). O enigma da igualdade. Revista Estudos Feministas, 13, 8-30.

Scott, J. (1995). Gênero: uma categoria útil de análise histórica. Revista Educação e Realidade, $16,12-25$.

Silva, N. F. (2009). A análise sobre a participação das mulheres e suas organizações na economia solidária no Brasil. Relatório de Pesquisa. REDES/IICA - MDA - NEAD - Brasília.

Silva, N. F. (2008). Relatório técnico contendo análise sobre a participação das mulheres e suas organizações na economia solidária no Brasil.Rio de Janeiro: Projeto de Cooperação Técnica IICA/MDA/NEAD.

Singer, P. (2002). Introdução àeconomia solidária (1 Ed). São Paulo: Editora Fundação Perseu Abramo.

Singer, P.; Souza, A. R. (2000). A economia solidária no Brasil: a autogestão como resposta ao desemprego. São Paulo: Contexto. 
Strassmann, D. (2002). A economia feminista. In N. Farias; M. Nobre (Orgs.), Economia feminista. SOF, São Paulo. 